\title{
Mixed Methods in Human Resource Development: Reviewing the Research Literature
}

\author{
Asif Ali Rahman ${ }^{1} \&$ Mohammad Omar Shiddike \\ ${ }^{1}$ Faculty of Education, University of Regina, Canada \\ Correspondence: Asif Ali Rahman, Ph.D. Candidate, Faculty of Education, University of Regina, Regina, SK, \\ S4S0A2, Canada. E-mail: rahman5a@uregina.ca \\ Received: January 14, 2020 \\ Accepted: February 5, 2020 \\ Online Published: February 15, 2020 \\ doi:10.5539/ijbm.v15n3p25 \\ URL: https://doi.org/10.5539/ijbm.v15n3p25
}

\begin{abstract}
This paper is written with a novice social sciences researcher (management, education, public administration, public policy, and human resource development etc.) in mind at the graduate or doctoral level. A mixed methods research design has been made in this paper for a human resource development (HRD) project after extensively reviewing the research literature. This paper is useful for researchers who are looking for a mixed methods research design plan based on a real-world example that can be adapted to their specific research. The paper is based on a research titled, "Transfer of Training: A mixed methods research". It explains a rationale for the use of mixed methods in an HRD project, followed by the research questions, the research methods and procedures. The paper also debates on sampling and data integration issues, data types, research instruments, data organization and cleaning, data analysis using software such as SPSS and NVIVO and issues of validity and reliability. The paper concludes with a discussion on limitations and delimitations.
\end{abstract}

Keywords: mixed methods research, training, transfer of training, human resource development, training and development, research design

\section{Introduction \& Background}

\subsection{Introduction}

This study is based on a convergent mixed methods research design (Tashakkori \& Teddlie, 2010). A convergent mixed methods research design is a procedure for collecting both quantitative and qualitative data from a sample and then merging them in the results stage to get a final conclusion (Creswell \& Plano Clark, 2018). A mixed methods research design is desirable as compared to a quantitative or qualitative study alone because mixed methods is believed to have many added advantages like providing a complete picture of the problem being researched (Plano Clark \& Ivankova, 2016). Since the study involves both quantitative and qualitative components, pragmatism has been chosen as a philosophical worldview of the study to avoid any paradigm clash (Morgan, 2014).

The paper has been divided into three sections. The first section Introduction \& Background to the study covers the context of the research, research problem, and the significance of the study. The second section Research Design Plan discusses the theory and practice of mixed methods research, rationale, the purpose and the research questions, data collection, research design, trustworthiness, credibility, and transferability, and limitations and delimitations of the study. The third and final section Summary \& Conclusion summarizes and concludes the paper.

\subsection{The Context of the Research}

This research has been designed from a developing country's perspective but can be applied anywhere around the world. The topic of the research is training transfer and the country of research is Pakistan. Although training transfer remains a new concept, a number of training firms and consultancies have emerged in Pakistan since the mid-1990s. Much of the training transfer research literature in the country is no more than six or seven years old (Khalid, Hanif, \& Laila, 2017; Qureshi, Bhutto, \& Tunio, 2017; Shiddike, 2019). Moreover, data about how much money is spent annually on training by the public and private sectors are unavailable, and the lack of relevant data makes it difficult to measure the rate of training transfer. The literature indicates that in North America and Europe, the rate of training transfer is believed to be around $15-30 \%$, though, this figure of $15-$ $30 \%$ has never been proven scientifically (Fitzpatrick, 2001; Saks, 2002). 
The research study, is conducted in Lahore (a major commercial city) in Pakistan and adopts mixed methods approach in data collection. 200 survey questionnaires are distributed to employees in eight major corporations of the city. The survey is followed by semi-structured in-depth interviews conducted with three employees in each of the eight corporations.

\subsection{Research Problem}

Over the past few decades, extensive research has been conducted on training transfer to increase the transfer of knowledge, skills, and attitudes acquired in a training context to a job. Training transfer is defined as the degree to which trainees effectively apply the knowledge, skills, and attitudes gained in a training context to the job (Newstrom, 1984; Wexley \& Latham, 1981). Since training is utilized in almost every discipline, researchers in the fields of management, education, human resource development, psychology, performance management, organizational behaviour, adult training, and nursing have explored the transfer problem in those fields. This diversity among researchers has resulted in inconsistent measures of training transfer, and substantial variations in findings (Blume, Ford, Baldwin, \& Huang, 2010).

Baldwin and Ford (1988) have played a pivotal role in providing some clarity and substance to the training transfer literature through their extensive literature review from 1907 to 1988. Recently, the authors conducted an updated extensive literature review on training transfer from 1988 to 2008 (Baldwin, Ford, \& Blume, 2009). In their review of the literature, Baldwin et al. identified the trends and emerging theories in the field of training transfer, and also indicated areas for further research by highlighting gaps in the research. In addition, the American Psychological Association (APA) published an article (Bell, Tannenbaum, Ford, Noe, \& Kraiger, 2017) in which the authors summarized research findings in training and development published in the Journal of Applied Psychology in the last 100 years. Bell et al. (2017) discuss their findings under four key research categories, which are training criteria, trainee characteristics, training design and delivery, and the training context. Like Baldwin and Ford, the authors also offered areas for further research in the four research categories. In spite of these research efforts, and a heightened interest in the concept, the rate of training transfer by employees to their jobs remains minimal (Cheema \& Syed, 2014; Holton, 2008; Khalid et al., 2017).

Training transfer can only occur after a certain learning experience (Baldwin et al., 2009). According to Baldwin et al., many pre- and post-training influences on training can have a direct effect on the training transfer. For example, influences like factors that motivate or demotivate employees, an opportunity to use skills learned during the training on the job, self-confidence of employees, a belief that training will result in positive outcomes from the point of view of rewards as well as performance, a choice to participate in training, a motivation to improve work through learning, work environment, worker/supervisor relationship, feedback and coaching, openness to change, and supervisors' attitude towards new knowledge and its use can affect training transfer in organizations. According to Baldwin et al. (2009), much of the traditional transfer research has taken an 'all things equal' perspective, which indicates that most trainees have roughly the same circumstances when they enter or leave training. Moreover, Baldwin et al. argue that traditionally training has mostly been seen as a static and a unidirectional experience. This perspective indicates that training has traditionally been viewed as the transfer of knowledge, skills, and attitudes from the trainer to the trainee, rather than as a bidirectional exchange of knowledge, skills, and attitudes between the trainer and trainees. One wonders if the static and unidirectional conceptualization of 'training' and 'transfer' contributes to a lack of training transfer in organizations.

\subsection{The Significance of the Study}

The study is significant because it contributes to the understanding of the experiences of employees (trainees) with the transfer problem in eight organizations of Pakistan (Rahman \& Shiddike, 2019). Thus, the findings of this study are likely to be most relevant for the eight organizations where the study is conducted. In addition, the study provides a useful contribution to the human resource development literature about the transfer problem in organizations.

Furthermore, the findings of the study may become a basis to offer best practices, solutions, and recommendations to other organizations across Pakistan that have similar experiences and challenges with the transfer problem. Thus, the findings are important not only for the studied organization but also for other organizations in the country that may be struggling with similar challenges.

In addition, the study addresses employees' concerns about the transfer problem for themselves, their teams, and the organization. The recommendations and suggestions arising from the study reveals the employees' preferred approach to addressing the transfer problem in their organizations. Thus, the recommendations may be used to enhance the transfer process in their organizations (Shiddike \& Rahman, 2019). The study provides not only a readiness analysis but also a comprehensive theoretical foundation for the transfer problem for the studied 
organizations. Thus, decisions or relevant policies made based on the research findings are grounded in a solid research foundation.

Finally, the study is significant in contributing to the current body of literature on the transfer problem in Pakistan, as only limited research is currently available. Much of the current research and publications on the transfer problem come from the experiences of the organizations in developed countries. Only a few academic publications in the contemporary Pakistani literature associated with the transfer problem are available. The study focuses on generating a theory on the transfer problem from the employees' perspective. Accordingly, the study contributes to the current body of literature about the transfer problem in organizations.

\section{Research Design Plan}

\subsection{The Theory \& Practice of Mixed Methods Research}

It is imperative for a researcher to understand the nature of mixed methods research before attempting to prepare a research design plan. According to Creswell and Plano Clark (2018), the nature of mixed methods include (1) the definition of mixed methods, (2) evaluating the examples and practice of mixed methods, (3) identifying what kind of research problems would require mixed methods, (4) knowing the benefits of mixed methods, and (5) recognizing the challenges and complexities of using mixed methods. Plano Clark and Creswell (2008) argue that a philosophical or theoretical grounding is necessary for all researchers (qualitative, quantitative, or mixed methods) but is absolutely essential for mixed methods researchers to truly understand the basis of mixed methods research. They further emphasize that a deep analysis of the theoretical evolution of mixed methods gives the researcher the necessary knowledge and skills to defend their research approach.

By analyzing the label of mixed methods, one cannot help but wonder that there seems to be some kind of collection of multiple data types and certain integration among them. Some scholars have been more conservative in their approach advocating that there should be some integration among data types in at least one stage of research (Creswell, 2015), while others like Greene (2007) support a more saturation of qualitative and quantitative data types during research (Creamer, 2016, 2018).

According to Creamer (2018) and Creswell and Plano Clark (2018), a number of definitions of mixed methods have emerged over the years. While there are some generally agreed upon characteristics of mixed methods such as the mixing of different data types, there are other characteristics of mixed methods research on which certain disagreements still exist. An example is philosophical or paradigmatic foundations of mixed methods and the extent of mixing of different data types. Creswell and Plano Clark (2018) evaluated the definitions of mixed methods and presented the evolution in the following tabular form:

Table 1. Scholars and the orientation of their definitions

\begin{tabular}{ll}
\hline Scholars & Orientation of their definitions \\
\hline Greene, Caracelli, and Graham (1989) & Methods \\
Tashakkori and Teddlie (1998, 2010) & Methodology (The process of research) \\
Johnson, Onwuegbuzie, and Turner (2007) & Philosophy, methods \& methodology \\
Tashakkori and Creswell (2007) & Methodology \& methods \\
Greene (2007) & Using multiple ways to make sense of the social world \\
Creswell and Plano Clark (2007) & Methods, methodology \& philosophy \\
Creswell (2015) & Methods \& core characteristics \\
Hesse-Biber (2015) & Methods \& contested terrain \\
\hline
\end{tabular}

Source: Adapted from Creswell and Plano Clark (2018, p. 3).

The table indicates how different scholars have defined mixed methods over the years. Some scholars like Greene et al. (1989), Creswell (2015) and Hesse-Biber (2015) have emphasized the specific qualitative and quantitative methods used during the research. Other scholars such as Tashakkori and Teddlie $(1998,2010)$ have indicated how methodology (the process of research) is important in mixed methods research. There are still other scholars such as Johnson et al. (2007), Tashakkori and Creswell (2007), Greene (2007), and Creswell and 
Plano Clark (2007), who argue that philosophy, methods, and methodology are important for mixed methods research. Over the years, the research scholars have touted the need for a complete definition of mixed methods. After studying and analyzing the past definitions of mixed methods presented by different scholars, Creswell and Plano Clark (2018) define mixed methods as:

In mixed methods, the researcher collects and analyzes both qualitative and quantitative data rigorously in response to research questions and hypotheses, integrates (or mixes or combines) the two forms of data and their results, organizes these procedures into specific research designs then provide the logic and procedures for conducting the study, and frames these procedures within theory and philosophy (p. 5).

According to Creswell \& Clark, one way of better understanding mixed methods besides the analysis of definitions is by looking at various examples of mixed methods. Creswell and Clark provide instances in which mixed methods could be utilized in various ways. Some of them are given below:

(1) A researcher collects quantitative data using surveys and then validates it by collecting qualitative data using focus groups. In this way, the researcher will be able to find out if the findings of both the qualitative and quantitative data are the same.

(2) A researcher conducts a survey and collects quantitative data but then collects qualitative data by interviewing some of the people who were surveyed to find the reasons behind their answers on the survey.

(3) A researcher explores a topic by interviewing some people, analyzing the qualitative data and then developing a quantitative instrument from it. That instrument is then administered to a sample population to see if it can be generalized to the entire population or at least some portion of it.

(4) A researcher wants to evaluate a program being implemented to a community. The first step is to do a needs assessment using interviews, focus groups and discussions to understand what questions need to be addressed. After the implementation of that program, certain quantitative instruments are designed to measure the outcomes. Then a comparison of qualitative and quantitative data is made to measure the success of the program.

\subsection{Rationale}

This study is based on mixed methods research. Mixed methods research is important because of three factors: (1) mixed methods research is used in social, behavioural, and health sciences, (2) mixed methods research combines the paradigms of quantitative and qualitative research, and (3) the overall strength of the research lies in the combined use of quantitative and qualitative data collection methods.

Historically, researchers have been more inclined towards quantitative research methodologies based on the paradigm of physical science (Niaz, 2008). The empirical evidence provided by quantitative research was considered more credible and authentic since it was based on the philosophy of science. However, social sciences researchers argued that quantitative research methodologies lacked the interpretations needed to research human beings and society. Thus, social scientists started using qualitative research methodologies instead of quantitative research methodologies, and a long war followed between advocates of the two methodologies (Gage, 1989; Guba, 1990; Lincoln, 1989). According to Niaz (2008), education research has now reached a new consensus after the paradigm war. Instead of believing that qualitative research in social sciences should replace quantitative research, researchers now believe that both could work together. Quantitative and qualitative research if integrated could provide a complete solution to education research problems.

Mixed methods research has become increasingly popular in the social sciences but not without its own share of problems. For example, according to Eunice, Douglas, Dawn, Monique, and Pia (2008), paradigm purists argue that different paradigms of research could not be mixed together. The reason is that different paradigms of research have different knowledge claims based on their incompatible assumptions. However, Tashakkori and Teddlie (2010) argue that an integrated mixed methods paradigm of quantitative and qualitative research could enhance our understanding of the mixed methods research and contribute to the body of knowledge. According to Tashakkori and Creswell (2007), paradigmatic incompatibility is counterproductive to the overall research efforts. The researchers also acknowledge that paradigm pluralism is possible and the philosophical differences could be reconciled if there is a new guiding paradigm that accepts the mixed methods research by getting out of its orthodox mindset. For example, this new guiding paradigm could be interpretivism. According to Eunice et al., methodological pluralism is only natural as, in practice, every research question crosses the boundaries of paradigms.

There is a specific reason why a mixed methods approach has been chosen for this research. Niaz (2008) argues that it is very important in education research that the research problem dictates the research methodology used. 
The research problem for this study relates to the transfer problem in Pakistani organizations. Therefore, attempting to conduct research on training transfer and analyzing the participants' perceptions of the benefits and limitations of training transfer for employees and their organizations require an integrated research methodology that could employ the empirical evidence of the quantitative research as well as the interpretations provided by the qualitative research. Thus, the mixed methods research. One of the most convincing arguments in favour of using mixed methods research in this study is that quantitative or qualitative data collection and analysis alone could not answer the research questions. The research questions for this study utilizes the combined strengths of quantitative and qualitative data collection and analysis. Strong evidence in favour of mixed methods research is provided by Johnson and Onwuegbuzie (2004). These authors state: "Researchers should collect multiple data using different strategies, approaches, and methods in such a way that the resulting mixture or combination is likely to result in complementary strengths and non-overlapping weaknesses" (p. 18).

After deciding on the mixed methods research, the next logical step is to find a way to integrate the quantitative and qualitative components of the research. According to Eunice et al. (2008), it is necessary to devise an integrated strategy for mixed methods data analysis. Tashakkori and Teddlie (2010) also advocate the importance of an integration strategy for using quantitative and qualitative data in a systematic mixed methods research. Mixed methods research practices have become quite advanced in recent years. Several mixed methods research methodologies capable of linking research purpose to research methodology and integrating findings have been discussed in the literature (Creswell, 2014; Tashakkori \& Creswell, 2007; Tashakkori \& Teddlie, 2010). Caracelli and Greene (1997) explain two broad categories of mixed methods research design: component designs and integrated designs. One key difference between the two designs is that in the components design, different methods used remain discrete in the entire research process and the mixed approach is only adopted at the findings stage or at a stage when interpretations are necessary. Some of the examples of components design are expansion designs, triangulation, and complementarity. However, in the case of integrated designs, mixing takes place at every level of research. Nested, holistic, developmental, and transformative designs are all examples of integrated designs (Caracelli \& Greene, 1997). Therefore, fewer chances of incompatibilities of philosophies, paradigms, assumptions, and knowledge claims exist in component design than do in integrated designs.

According to Creswell (2015), it is important to understand the types of mixed methods design before integrating quantitative and qualitative research. Creswell explains the mixed methods research designs in three basic and three advanced types. The three basic mixed methods designs are as follows:

(1) A convergent design is a design in which both quantitative and qualitative data are collected and analyzed. The results of both are then merged for the purpose of comparison.

(2) An explanatory sequential design is a simple design in which the quantitative methods are used first and then the qualitative methods are used to explain the quantitative results.

(3) An exploratory sequential design is a design in which qualitative data is collected first because the research questions might not be fully known or understood. After this preliminary qualitative data exploration, the researcher would use the data to develop a second quantitative phase. This phase might include designing a quantitative instrument, preparing for an experimental intervention, or designing a typology that could be measured using existing instruments. In the third and final phase, the quantitative instrument, the experimental intervention, or the newly designed typology are used in quantitative data collection and analysis.

One of these three basic mixed methods designs is always found explicitly or implicitly in almost every mixed methods research. Sometimes, other advanced research features are added in the mixed methods research design. Creswell (2014) calls these the advanced mixed methods designs. The three most popular advanced mixed methods designs are as follows:

(4) Intervention design is a mixed method design in which the researcher employs one of the above mentioned basic mixed methods designs in a larger experimental framework. During the larger experiment, the researcher might use qualitative data collection and analysis.

(5) Social justice or transformative designs are those designs in which the researcher includes a social justice framework surrounding a convergent, explanatory, or exploratory mixed methods design. The social justice framework could be added at any phase of the research process, but its main purpose is to improve the lives of people.

(6) Multistage evaluation designs are the longitudinal studies that are conducted over a long period. These designs include a number of mixed methods studies. Thus, quantitative and qualitative studies revolve around a convergent, explanatory, or exploratory mixed methods design. 


\subsection{The Purpose \& the Research Questions}

The purpose of this study is to investigate the extent to which organizations in Pakistan deliver training activities that facilitate training transfer before, during and after training and the way the relationship between these three activities influence training transfer in these organizations. This is a mixed methods study based on convergent design. The four questions that will be investigated in the study are given below:

(1) What do the participants perceive as the benefits and limitations of training and training transfer for employees and their organizations?

(2) What contextual factors influence training transfer by trainees back to their jobs before, during and after training?

(3) What suggestions can the participants offer to foster training transfer in their organizations?

(4) In what ways do trainee characteristics influence training transfer before, during and after training?

The first and second questions are quantitative questions (the questions begin with the word what which indicates the presence of quantitative variables like benefits, limitations, and contextual factors) which will be addressed through employee questionnaire surveys. The third question is a qualitative question (the presence of qualitative variable like suggestions) which will be addressed through interviews. The fourth and final question is mixed methods question (the words in what ways draws attention to the qualitative component of the study, and the words do, trainee characteristics and influence relate to the quantitative components) that will be addressed through surveys and interviews both. According to Creswell and Plano Clark (2018) and Plano Clark and Creswell (2008), the purpose of a mixed methods question is to highlight the importance of the integration of quantitative and qualitative methods. It is also important to note that the following research questions are written in a particular order to follow the quantitative and qualitative phases of the convergent mixed methods research design used in this study. It is also important to note that only research questions and not a hypothesis is used in this study. The reason is that the hypothesis is only used in quantitative studies. Sometimes, when the hypothesis is used in the quantitative section of a mixed study, literature must have already provided some indication of predicted relationships "(e.g., men will display more aggression than women when considered in terms of sex-role stereotypes)" (Creswell \& Plano Clark, 2018, p. 164). Such kind of predicted relationship can then be used as a null hypothesis. However, this is not the case here and hence no hypothesis.

\subsection{Data Collection}

According to Creswell (2015), there are four criteria to follow in a mixed methods research. Based on this research, the four criteria are as follows:

\subsubsection{Research Guided by Research Questions}

The first criterion of the mixed methods research is that the quantitative and qualitative data collection and analysis must be in response to the research questions. In this research, the data collection and analysis for the four questions involves both quantitative and qualitative data. For example, quantitative and qualitative data focuses on the current state of training transfer in Pakistan. The contextual factors and the employee characteristics that influence training transfer in Pakistan is explored. The view that training can be designated a 'good-for-all' activity is also explored. Lastly, different reasons for positive and negative training transfer are investigated.

\subsubsection{Rigorous Research}

The second criterion of mixed methods research is that both quantitative and qualitative research should be rigorous. It has been made sure that this research is rigorous based on the following factors:

Research Design. This research is based on a convergent design of mixed methods. Since this research has been equally divided between quantitative and qualitative components and the results obtained from both of these components are merged at the final stage, the study falls under the category of convergent design. In this research, quantitative (survey) and qualitative (interviews) data collection and analysis are done first, and then the results of both quantitative and qualitative data are merged in the findings. The benefits of a convergent design are that it is possible to see the research problems from different perspectives due to different data types.

Sampling \& Integration. Sampling and integration are the two major challenges that the mixed methods researchers face (Creswell, 2014, 2015; Creswell \& Plano Clark, 2018; Plano Clark \& Creswell, 2008; Tashakkori \& Creswell, 2007). These challenges are normally referred to as 'methodological issues.' Sampling 
refers to the recruitment of the individuals who will participate in both quantitative and qualitative data collection. The major questions that linger in mixed methods data collection is the sample size for quantitative and qualitative data collection. How will the survey instrument be distributed among the target population? What kind of permissions are needed for data collection from the research institute as well as the organizations in which the research is to be conducted? Will the sample sizes for quantitative and qualitative data collection be the same or different? What kind of formula should be used to calculate the sample sizes of quantitative as well as qualitative data collection? The answers to these questions as they relate to my study are provided in the following paragraphs.

Sampling. Two major considerations for quantitative and qualitative sampling are considered in this research. The first consideration is that the appropriate sample size chosen is truly representative of the entire target population. Secondly, the sampling procedures and methods used in both quantitative and qualitative data collection are rigorous. Since surveys are being used for quantitative data collection, simple random sampling is used as a sampling method. According to Creswell (2015) and Creswell and Plano Clark (2018), a good sampling strategy for quantitative research is simple random sampling. In addition, permission for fieldwork is sought from the University of Regina's Research Ethics Board as well as from the corporations invited to participate in the study. Individuals who are recruited are employees who are in a position to provide the necessary data.

Quantitative and qualitative sampling done in this research is given below in figure 1:

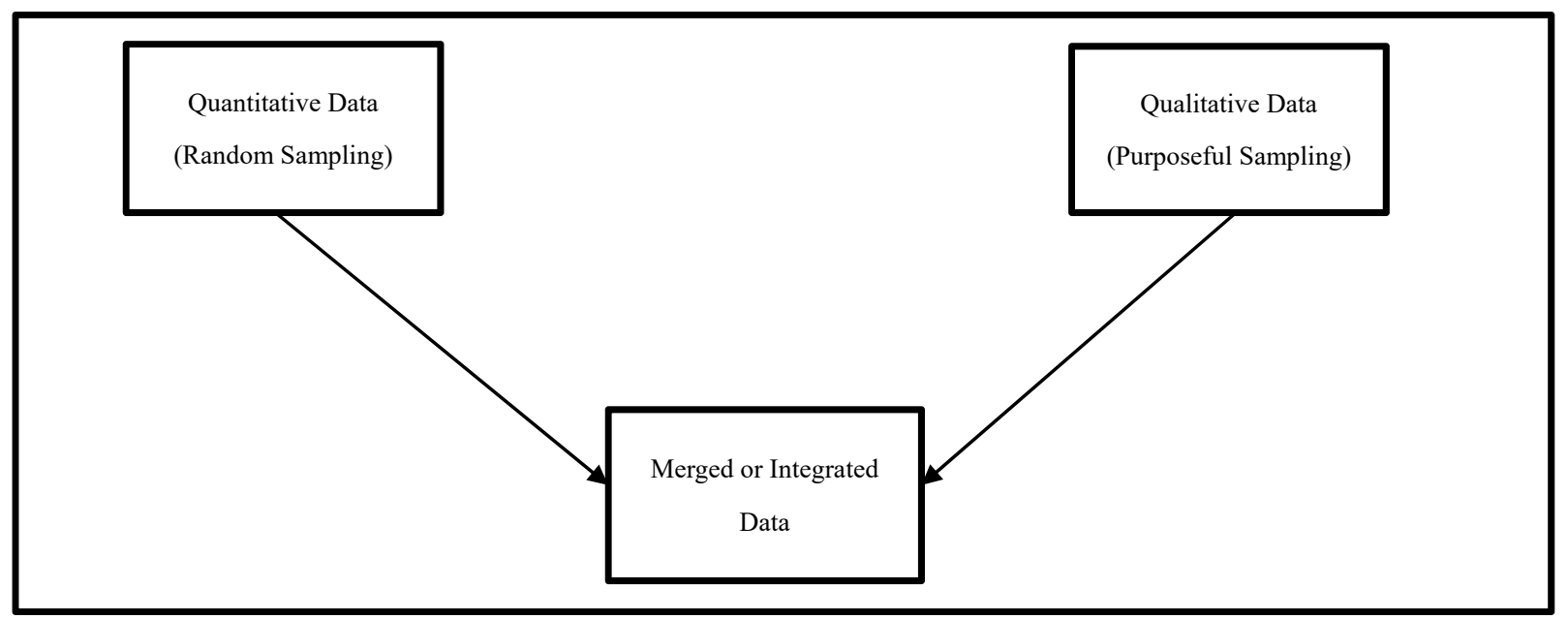

Figure 1. Sampling in a convergent design

Source: Adapted from Creswell (2015, p. 78).

Sample and Sample Size. This research is conducted in eight corporations of Lahore which is a major Pakistani city. 200 questionnaires are mailed to the employees in each of the eight corporations invited to participate in the study. In addition, semi-structured in-depth interviews are conducted with three employees from each organization. The participants recruited for the study are employees who have participated in training over the last three years.

Data Types. The types of data collected are audio recordings, text, and questionnaire responses.

Research Instruments. The instruments used to collect the data are surveys and open-ended, in-depth interviews.

Data Integration. According to Creswell (2015), data "integration refers to how one brings together the qualitative and quantitative results in mixed methods study. The way the researcher combines the data needs to relate to the type of mixed methods design used" (p. 75)(p. 75)(p. 75)(p. 75)(p. 75). Integration involves the intersection of the quantitative and qualitative data. In other words, integration is used as an alternative term for the mixing of the quantitative and qualitative data. Integration of data normally occurs in one of these three stages: data collection stage, data analysis stage, or results stage. In this study, the data integration occurs during the results stage. A graphic representation of integration in this study is provided in figure 2 . 


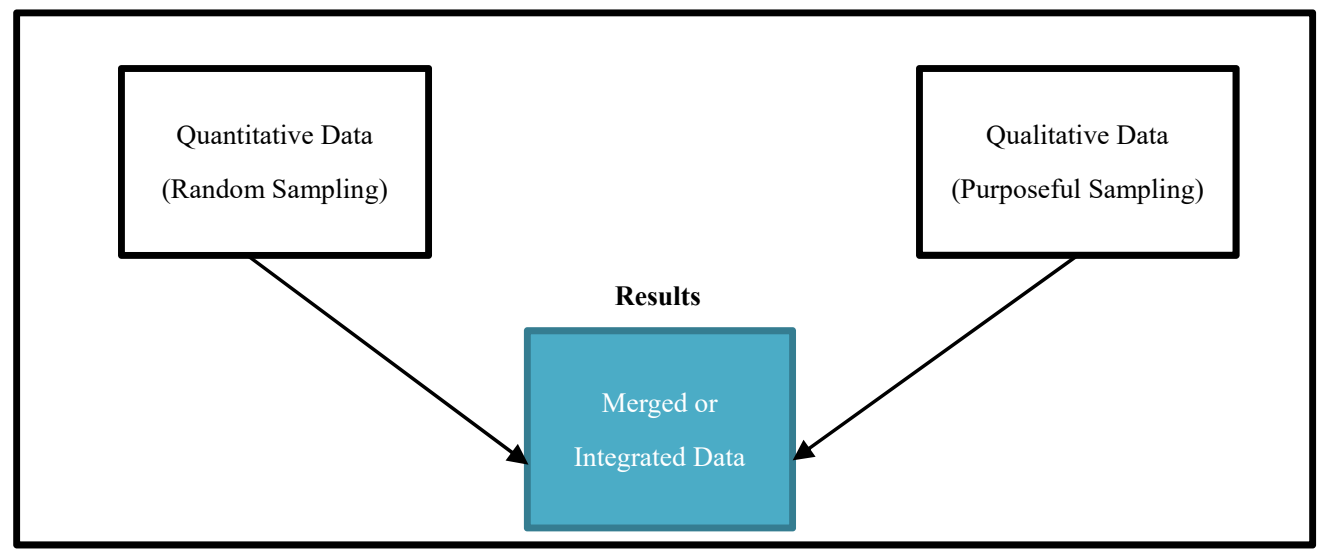

Figure 2. Integration in a convergent design

Source: Adapted from Creswell (2015, p. 84).

Data Organization \& Cleaning. Data organization and cleaning is done using the computer as the first step in data analysis.

\subsubsection{Merging of Quantitative \& Qualitative Data}

According to the third criterion of mixed methods research, the quantitative and qualitative data is combined. As it has already been mentioned that this research is based on a convergent design. In this research design, quantitative and qualitative data are collected and analyzed. Then quantitative and qualitative data are merged and interpreted.

\subsubsection{Data Analysis}

The fourth criterion of mixed methods is data analysis and interpretation. Quantitative data analysis is done using statistical software such as SPSS. Qualitative data analysis is also done on the computer using software such as NVIVO.

\subsection{Research Design}

This mixed methods research study follows a simple convergent design. The convergent design is the most popular form of mixed methods. Often when the term mixed methods is used, a convergent design comes in mind. The idea of a convergent design began in the 1970s when scholars started combining quantitative and qualitative results to get a complete picture. Since the 1970s, the convergent design has been known by many names like parallel study, simultaneous triangulation, convergent model, and concurrent triangulation (Creamer, 2018; Creswell, 2015; Creswell \& Plano Clark, 2007, 2018; Plano Clark \& Ivankova, 2016; Tashakkori \& Teddlie, 1998, 2010).

The intent of the convergent design is to combine the strengths and weaknesses of quantitative and qualitative research "(e.g., quantitatively, a large sample size, objective measures, trends, and generalization combined with, qualitatively a small sample, subjective interpretation, details, and depth)" (Creswell \& Plano Clark, 2018, p. 68). This research design is used when researchers want to get the complete picture by combining the statistical analysis/results of the quantitative data and qualitative findings.

Since both quantitative and qualitative data are used in this study, there is a chance of a clash between philosophical paradigms. Therefore, pragmatism is used as a philosophical worldview of a convergent mixed methods research design used in this study (Creswell \& Plano Clark, 2018; Morgan, 2014). There are many reasons for choosing pragmatism. Most of the scholars of mixed methods (Creswell, 2014, 2015; Creswell \& Plano Clark, 2018; Morgan, 2014; Tashakkori \& Teddlie, 2010) believe that pragmatism is the best fit for mixed methods study. According to Tashakkori and Teddlie, linking pragmatism to mixed methods can have the following benefits:

(1) Both quantitative and qualitative methods can be used in a single study.

(2) Research questions are given the primary importance instead of research methods or philosophical worldview used in a study.

(3) The confusion of using multiple paradigms in a study is abandoned. 
(4) The use of metaphysical concepts such as truth and reality are also abandoned.

(5) A practical and applied philosophy guides the entire research.

\subsection{Trustworthiness, Credibility, and Transferability}

Validity and reliability are important components of research. Validity is the degree of dependability, credibility, and value attached to the findings of a study (Zohrabi, 2013). According to Merriam (1998), it is up to the researcher to build validity in all phases of the research. Since it is imperative that the data and the instruments are validated, the following measures are used for this study. Content validity is ensured by making the instruments as close to the research questions as possible (McKim, 2017). An effort has been made to make the survey and interview questions as clear as possible. The fact that this is a mixed method study itself warrants internal validity because two different kinds of instruments, surveys and interviews are used for data collection. According to Onwuegbuzie and Johnson (2006), when two or more instruments are used in data collection, they act as a counter check and counter validate each other. Collection of data using different instruments is also called triangulation. Peer examination is also conducted to validate the data (Zohrabi, 2013). Certain field experts have been identified in Pakistan who are familiar with the topic for this study. They evaluate and validate the data collected in this study. Another factor which has been considered in this study is external validity. Training transfer research has been rarely attempted in a developing country setting. Training transfer in Pakistan will shed some new light on the subject and might contribute to the body of literature on human resource development.

Reliability is another important requirement in research. Reliability means consistency, dependability and replicability of the findings of the study (Zohrabi, 2013). Consistency, dependability and replicability in the quantitative component of this research are easy to achieve. The findings are replicable because the same survey instruments could be used in different organizational settings. Reliability of the qualitative component of this research are maintained making the study rigorous. Dependability and reliability are achieved by explaining every phase of the research in detail. Triangulation techniques is achieved through the use of surveys and interviews. Triangulation also increases the overall reliability of the research.

\subsection{Limitations and Delimitations}

The limitations of the study relate to the characteristics of the methodology used, which set parameters on the application or interpretation of the results of the study. One limitation of the study might be the constraints on the utility of the findings of the study due to the lack of generalizability. This study investigates the transfer problem in eight organizations of Pakistan. Thus, the findings of the study may be limited only to these organizations. However, readers of the study are able to compare the findings to the transfer problem in similar and dissimilar organizational contexts in the country to determine the transferability of the findings to their organizations.

In addition, the study focuses on understanding only employee perspectives on the transfer problem in their respective organizations. Thus, the views of other stakeholder groups, such as management, suppliers, customers, and policymakers are not incorporated into the study. Further, the study is based on the experiences of participants who volunteer to participate in the research. Therefore, the views of employees who decide not to participate for various reasons are not incorporated into this study. Finally, data for the study is collected through one-on-one in-depth interviews and a survey questionnaire only. There is no extensive reviews of the participants' employment documents and records because of issues of confidentiality.

The findings of this study are delimited by researchers' decision to recruit participants from eight organizations in one Pakistani city. That decision is driven primarily by resource constraints, especially time constraints, for fieldwork.

\section{Summary and Conclusion}

This is a mixed methods study conducted in Pakistan. The topic of study is "Transfer of Training: A mixed methods research". Training transfer research has never been attempted before in a developing country's setting. This research is conducted in eight corporations of Lahore which is a major Pakistani city. 200 questionnaires are mailed to employees in each of the eight corporations invited to participate in the study. In addition, semi-structured in-depth interviews are conducted with three employees from each organization. The participants recruited for the study are employees who have participated in training over the last three years.

Moreover, this paper discusses a rationale for the use of mixed methods, followed by the research questions, the research methods and procedures. The paper also discusses sampling and data integration issues, data types, research instruments, data organization and cleaning, data analysis using software such as SPSS and NVIVO and issues of validity and reliability. This paper concludes with a discussion on limitations and delimitations. 


\section{References}

Baldwin, T. T., \& Ford, J. K. (1988). Transfer of training: A review and directions for future research. Personnel Psychology, 41(1), 63-105. https://doi.org/10.1111/j.1744-6570.1988.tb00632.x

Baldwin, T. T., Ford, J. K., \& Blume, B. D. (2009). Transfer of training 1988-2008: An updated review and new agenda for future research. In G. P. Hodgekinson \& J. K. Ford (Eds.), International review of industrial and organizational psychology (Vol. 24, pp. 41-70). Chichester, UK: Wiley.

Bell, B. S., Tannenbaum, S. I., Ford, J., Noe, R., \& Kraiger, K. (2017). 100 years of training and development research: What we know and where we should go. Journal of Applied Psychology, 102(3), 305-323. https://doi.org/10.1037/ap10000142

Blume, B. D., Ford, J. K., Baldwin, T. T., \& Huang, J. L. (2010). Transfer of training: A meta-analytic review. Journal of Management, 36(4), 1065-1105. https://doi.org/10.1177/0149206309352880

Caracelli, V. J., \& Greene, J. C. (1997). Crafting mixed method evaluation designs. In V. J. Caracelli \& J. C. Greene (Eds.), Advances in mixed methods evaluation: The challenges and benefits of integrating diverse paradigms (pp. 19-32). San Francisco, CA: Jossey-Bass.

Cheema, F. E. A., \& Syed, N. A. (2014). Issues of transfer of training from the training houses to the line department: A case of government sector department in Pakistan. IBT Journal of Business Studies, 9(1), $150-158$.

Creamer, E. G. (2016). A Primer about mixed methods research in an educational context. International Journal of Learning, Teaching, and Education Research, 15(8), 1-13.

Creamer, E. G. (2018). An introduction to fully integrated mixed methods research. Thousand Oaks, CA: Sage Publications.

Creswell, J. W. (2014). Mixed methods procedures. In J. W. Creswell (Ed.), Research design: Qualitative, quantitative, and mixed methods approaches. Thousand Oaks, California: Sage.

Creswell, J. W. (2015). A concise introduction to mixed methods research. Thousand Oaks, CA: Sage Publications.

Creswell, J. W., \& Plano Clark, V. (2007). Designing and conducting mixed methods research. Thousand Oaks, CA: Sage.

Creswell, J. W., \& Plano Clark, V. (2018). Designing and conducting mixed methods research (3rd ed.). Los Angeles: Sage Publications.

Eunice, E. J., Douglas, E. M., Dawn, P., Monique, H., \& Pia, R. (2008). Integrative mixed methods data analytic strategies in research on school success in challenging circumstances. Journal of Mixed Methods Research, 2(3), 221-247. https://doi.org/10.1177/1558689808315323

Fitzpatrick, R. (2001). The strange case of the transfer of training estimate. The Industrial-Organizational Psychologist, 39(2), 18-19.

Gage, N. L. (1989). The paradigm wars and their aftermath: A "historical" sketch of research on teaching since 1989. Educational Researcher, 18(7), 4-10. https://doi.org/10.3102/0013189X018007004

Greene, J. C. (2007). Mixed methods in social inquiry. San Francisco, CA: Jossey-Bass.

Greene, J. C., Caracelli, V. J., \& Graham, W. F. (1989). Toward a conceptual framework for mixed-method evaluation designs. Educational Evaluation and Policy Analysis, 11(3), 255-274. https://doi.org/10.2307/1163620

Guba, E. G. (1990). The alternative paradigm dialog. In E. G. Guba (Ed.), The paradigm dialog (pp. 17-27). Newbury Park, CA: Sage.

Hesse-Biber, S. N. (2015). Introduction: Navigating a turbulent research landscape: Working the boundaries, tensions, diversity, and contradictions of multimethod and mixed methods inquiry. In S. N. Hesse-Biber \& R. B. Johnson (Eds.), The Oxford handbook of multimethod and mixed methods research inquiry (pp. xxxiii-liii). Oxford, UK: Oxford University Press.

Holton, E. (2008). Why training transfer is a critical problem. Retrieved from https://www.youtube.com/watch?v=VBDroHrTNz8\&t=2s 
Johnson, R. B., \& Onwuegbuzie, A. J. (2004). Mixed methods research: A research paradigm whose time has come. Educational Researcher, 33(7), 14-26. https://doi.org/10.3102/0013189X033007014

Johnson, R. B., Onwuegbuzie, A. J., \& Turner, L. A. (2007). Toward a definition of mixed methods research. Journal of Mixed Methods Research, 1(2), 112-133. https://doi.org/10.1177/1558689806298224

Khalid, M., Hanif, A., \& Laila, U. (2017). Transfer of training \& the challenges: NADRA A case study. International Review of Management and Business Research, 6(1), 274-288.

Lincoln, Y. S. (1989). Trouble in the land: The paradigm revolution in the academic disciplines. In J. C. Smart (Ed.), Higher education: Handbook of theory and Research (pp. 57-133). New York: Agathon Press.

McKim, C. A. (2017). The value of mixed methods research: A mixed methods study. Journal of Mixed Methods Research, 11(2), 202-222. https://doi.org/10.1177/1558689815607096

Merriam, S. B. (1998). Qualitative research and case study applications in education. San Francisco: Jossey-Bass.

Morgan, D. L. (2014). Integrating qualitative and quantitative methods: A pragmatic approach. Thousand Oaks, CA: Sage Publications.

Newstrom, J. W. (1984). A role-taker/time differentiated integration of transfer strategies. Paper presented at the 1984 meeting of the American Psychological Association (APA), Toronto, Ontario.

Niaz, M. (2008). A rationale for mixed methods (integrative) research programmes in education. Journal of Philosophy of Education, 42(2), 287-305. https://doi.org/10.1111/j.1467-9752.2008.00625.x

Onwuegbuzie, A. J., \& Johnson, R. B. (2006). The validity issue in mixed research. Research in the Schools, 13(1), 48-63.

Plano Clark, V., \& Creswell, J. W. (2008). The mixed methods reader. Thousand Oaks, United States: Sage Publications.

Plano Clark, V., \& Ivankova, T. (2016). Mixed methods research: A guide to the field. Thousand Oaks, CA: Sage Publications.

Qureshi, Q.-u.-A., Bhutto, A., \& Tunio, R. A. (2017). Factor affecting the transfer of training at the workplace: Case study of SSGC Ltd, Pakistan. International Journal of Academic Research in Business and Social Sciences, 7(2), 357-370.

Rahman, A. A., \& Shiddike, M. O. (2019). Agendas for future training transfer research: Pakistan's perspective. Developing Country Studies, 9(4), 39-48. https://doi.org/10.7176/DCS/9-4-06

Saks, A. (2002). So what is a good transfer of training estimate? A reply to Fitzpatrick. The Industrial-Organizational Psychologist, 39, 28-30.

Shiddike, M. O. (2019). A case study of teacher engagement in partisan politics and it's influences on students learning and classroom practices: Perspective on Bangladesh. World journal of education, 9(3), 22-29. https://doi.org/10.5430/wje.v9n3p22

Shiddike, M. O., \& Rahman, A. A. (2019). Engaging faculty in professional development: Lessons from Bangladesh. Journal of Educational and Developmental Psychology, 9(2), 124-137. https://ddoi.org/10.5539/jedp.v9n2p124

Tashakkori, A., \& Creswell, J. W. (2007). Editorial: The new era of mixed methods. Journal of Mixed Methods Research, 1(1), 3-7.

Tashakkori, A., \& Teddlie, C. (1998). Mixed methodology: Combining qualitative and quantitative approaches. Thousand Oaks, CA: Sage Publications.

Tashakkori, A., \& Teddlie, C. (2010). SAGE handbook of mixed methods in social \& behavioral research (2 ed.). Thousand Oaks, California: Sage.

Wexley, K. N., \& Latham, G. P. (1981). Developing and training human resources in organizations. Glenview, IL: Scott Foresman.

Zohrabi, M. (2013). Mixed method research: instruments, validity, reliability and reporting findings. Theory and Practice in Language Studies, 3(2), 254-262. https://doi.org/10.4304/tpls.3.2.254-262 


\section{Copyrights}

Copyright for this article is retained by the author(s), with first publication rights granted to the journal.

This is an open-access article distributed under the terms and conditions of the Creative Commons Attribution license (http://creativecommons.org/licenses/by/4.0/). 